\title{
Deep and Meaningful E-Learning with Social Virtual Reality Environments in Higher Education: A Systematic Literature Review
}

\author{
Stylianos Mystakidis ${ }^{1, *(D)}$, Eleni Berki ${ }^{2}$ and Juri-Petri Valtanen ${ }^{3}$ \\ 1 School of Natural Sciences, University of Patras, GR-2504 Patras, Greece \\ 2 Faculty of Information Technology, University of Jyväskylä, FI-40014 Jyväskylä, Finland; eleni.e.berki@jyu.fi \\ or eleniberki1@gmail.com \\ 3 Faculty of Education and Culture, Tampere University, FI-33100 Tampere, Finland; \\ valtanenjuripetri@gmail.com \\ * Correspondence: smyst@upatras.gr; Tel.: +30-2610996732
}

\section{check for}

updates

Citation: Mystakidis, S.; Berki, E.; Valtanen, J.-P. Deep and Meaningful E-Learning with Social Virtual Reality Environments in Higher Education: A Systematic Literature Review. Appl. Sci. 2021, 11, 2412. https://doi.org/ 10.3390/app11052412

Received: 4 February 2021

Accepted: 4 March 2021

Published: 9 March 2021

Publisher's Note: MDPI stays neutral with regard to jurisdictional claims in published maps and institutional affiliations.

Copyright: (c) 2021 by the authors. Licensee MDPI, Basel, Switzerland. This article is an open access article distributed under the terms and conditions of the Creative Commons Attribution (CC BY) license (https:// creativecommons.org/licenses/by/ $4.0 /)$.
Abstract: Deep and meaningful learning (DML) in distant education should be an essential outcome of quality education. In this literature review, we focus on e-learning effectiveness along with the factors and conditions leading to DML when using social virtual reality environments (SVREs) in distance mode higher education (HE). Hence, a systematic literature review was conducted summarizing the findings from thirty-three empirical studies in HE between 2004 (appearance of VR) and 2019 (before coronavirus appearance). We searched for the cognitive, social, and affective aspects of DML in a research framework and studied their weight in SVREs. The findings suggest that the use of SVREs can provide authentic, simulated, cognitively challenging experiences in engaging, motivating environments for open-ended social and collaborative interactions and intentional, personalized learning. Furthermore, the findings indicate that educators and SVRE designers need to place more emphasis on the socio-cultural semiotics and emotional aspects of e-learning and ethical issues such as privacy and security. The mediating factors for DML in SVREs were accumulated and classified in the resultant Blended Model for Deep and Meaningful e-learning in SVREs. Improvement recommendations include meaningful contexts, purposeful activation, learner agency, intrinsic emotional engagement, holistic social integration, and meticulous user obstacle removal.

Keywords: social virtual reality environments (SVREs); distance education; open and distance learning (ODL); e-learning; deep and meaningful learning (DML); systematic literature review (SLR); higher education (HE)

\section{Introduction}

In a constantly changing information society where knowledge organizations and educational institutions support a knowledge-based economy and the citizens' well-being, there is a social need to continuously improve the quality of all modes of learning. The quality improvements should aim to enhance or at least bring about meaningful reforms to all levels of formal education, supporting the learners' styles of learning and their personalized learning needs. Higher education (HE) is often the most turbulent domain of externally or/and internally or time-driven changes. Such rapid or slow changes are, for instance, the current coronavirus pandemic or various socio-economical changes from financial crises, which most often define the needs for a specific type and mode of learning, re-shaping pedagogic purposes of state-based or other formal education. For learning processes to be both effective with desirable results (learning outcomes) and also efficient regarding the performance of instructors and learners, long- and short-term educational objectives must be clearly outlined and smoothly streamlined. In return, the learning procedures must be thoroughly (re-)considered and often re-designed or adapted to address the newly risen pedagogical, socio-cultural, or socio-economical needs. 
The learning procedure itself is a complex mental phenomenon involving cognitive processing [1], taking place in a social and cultural setting through direct and indirect contact with other human actors [2]. This procedure generates feelings and is influenced by the learner's affective states and predispositions [3]. Hence, personal learning processes broadly encompass three essential elements: content, social interaction, and incentives, where each element is linked to its respective dimension (cognitive or logical; emotional or affective; and social or intrapersonal) [4]. The augmentation of all aforementioned dimensions has the intended result of quality learning that resonates, is durable, carries personal meaning, is integrated cognitively, and can be applied in different contexts. It can be argued by the authors that this description is summarized via the concept of deep and meaningful learning (DML). The latter should be rich and polymorphic as well as multileveled, by its very nature, as explained next.

Deep learning stems from the research carried out by Marton and Säljö [5,6] on the processing approaches of students while executing cognitive tasks. A learner who uses deep learning approaches and takes control of his or her learning attempts to essentially understand the learning content and process and tries to make sense of and transform the organization of the self [5]. Ohlsson defines deep learning as the capability for fundamentally radical cognitive growth, that he calls non-monotonic [7]. He particularly distinguishes three types of non-monotonic change in cognition, briefly mentioned next:

(1) Capacity for novel solution generation and creative insights;

(2) Modification of cognitive skills by trial and error;

(3) Conversion of beliefs through critical reflection [7].

Otherwise stated, deep learning occurs when students/learners are actively involved in the learning process and are given opportunities to construct meaning [8]. Deep learning is linked to manifold (i.e., creative, critical, reflective, and caring) thinking [9] and problemsolving processes and capabilities [10].

Meaningful learning, according to Ausubel [11], should be the goal of formal higher education, which is achieved through sustained critical discourse. Learning itself becomes meaningful when it exhibits five descriptive characteristics: active, constructive, intentional, authentic, cooperative [6,12].

The two previously explained concepts—-deep learning and meaningful learninghave been combined and unified into the term deep and meaningful learning, as there are correspondences in their conceptualization and construction [13] that can encompass enhanced quality learning in reality.

How could DML be facilitated in reality? Both deep learning and meaningful learning theories confirm that quality learning experiences activate students' minds, hearts, and interpersonal communication skills [14,15]. DML achievement is a challenge in all educational settings considering that the key stakeholder of the learning process is each and every learner with his/her unique characteristics and mental and emotional capacities [16]. Educational institutions and knowledge providers, through their teaching and administrative staff, need to design and implement multi-faceted quality learning experiences that enable deep learning. Information and communication technology could support meaningful learning when the it is used for knowledge construction, conversation, articulation, collaboration, and reflection [12].

Creating and supporting DML in e-learning settings is even more challenging. During 2020, many research projects [17-19] appeared to study many challenges that arose for learners and instructors from the increased and sudden use of e-learning facilities due to national lockdowns globally and a quick "must be" adaptation to new modes of open and distance learning. In particular, learners' emotions and motivational complexities have sometimes been neglected and it is often difficult to draw observations in distance education. For example, some affective aspects of learning such as interest and motivation are crucial as they have a direct impact on the cognitive learning procedures [20].

Humans can have multiple extrinsic and intrinsic goals and motives at the same time [21]. Their own learning objectives can vary a lot. HE students sometimes enter into 
learning with the objective to perform well and not to fail the summative assessment tests. Often, corporate employees participate in a training program with the objective to secure a monetary reward. These are examples of extrinsic goals associated with education [16]. Of course, extrinsic motivation leads to surface processing, anxiety and attrition [22] In other times, the same or other students can adopt intrinsic incentives associated with the joy of engaging with the studied subject itself [6]. High dropout rates in e-learning can often be attributed to emotional factors and conditions such as frustration, confusion, isolation, and lack of intrinsic motivation [23]. Educational practitioners and instructors do not necessarily possess the knowledge and/or the skills to motivate their audience and somehow engage them in learning, e.g., by incorporating relevant cooperative or collaborative group activities [24].

A social virtual reality environment (SVRE) appears to be a promising technology for learners' engagement due to the (learning) environment's potential to facilitate DML in virtual learning settings. Yet, this remains an idea and needs to be investigated in its application and practice. SVREs constitute three-dimensional computer-generated virtual reality spaces that are instrumental for social or psychological immersion [6]. In the research literature, SVREs are also called immersive virtual worlds or multi-user virtual environments (MUVEs) [6]. SVREs are accessible through computer technology while some of them can also be experienced through the use of head-mounted displays or mobile, hand-held devices.

A comparison between SVREs with two-dimensional (2D) learning environments yields significant differences related to context and interaction [25]. SVREs also elicit an enhanced sense of self in users through the avatar, a learner-controlled, personal, digital agent [26]. The embodied representation creates a feeling of belonging to a similar group and desire for being in a space where a strong co-presence could be experienced when meeting with other agents/avatars [27]. Essentially, SVREs appear to provide practitioners with the capacity to address, to some extent, two often neglected aspects in open and distance learning: social discourse and intrinsic motivation [6]. These aspects along with the learners' (cognitive) engagement are three vital (yet often missing) dimensions to enable DML. The combined study of these three elements, which are of great significance in achieving and eventually claiming quality (improvements) in open, distant, or virtual education, is placed as the focus of the systematic literature review that was carried out and is being reported herein. Hence, in this research study, we examined if and under what/which conditions the empirical research evidence supports the previous. Finally, we illustrate and critically comment on the findings from thirty-three studies that also deal with these three factors, examined in pairs-that is, the two dimensions considered only—or as a triplet—-that is, taking into account all three dimensions.

\section{Related Work}

One could claim that SVREs have (or have not) been widely used and studied. Thus, the particular research and evaluation results of this subject area could (or, again, not) please some learning stakeholders, especially if it is considered as under investigation. In our query for existing literature reviews, we discovered fifteen relevant publications synthesizing results from previous empirical studies. The characteristics of these reviews are summarized in Table 1. 
Table 1. Summary of reviews on Virtual Worlds in an educational context.

\begin{tabular}{|c|c|c|c|c|c|}
\hline Reference & Reviewed Articles (Years) & Subject & Level of Education ${ }^{1}$ & Mode & Focus \\
\hline Hew and Cheung, 2010 [28] & 15 (2001-2007) & All & $\mathrm{K}-12$ and $\mathrm{HE}$ & All & $\begin{array}{l}\text { Educational uses, research methods, topics, } \\
\text { and findings }\end{array}$ \\
\hline Sitzmann, 2011 [29] & 55 (1982-2009) & All & All & All & $\begin{array}{l}\text { Instuctional effectiveness of digital } \\
\text { simulation games }\end{array}$ \\
\hline Mikropoulos and Natsis, 2011 [30] & 53 (1999-2009) & All & All & All & $\begin{array}{l}\text { Educational contexts, pedagogical } \\
\text { approaches, features, and outcomes }\end{array}$ \\
\hline Inman et al., 2011 [31] & 27 (2003-2010) & All & $\mathrm{K}-12$ and $\mathrm{HE}$ & All & $\begin{array}{l}\text { Educational uses, research, methodology, } \\
\text { findings, and recommendations }\end{array}$ \\
\hline Ishbel et al., 2012 [33] & $100(1990-2011)$ & All & All & All & $\begin{array}{l}\text { Taxonomy of educational uses, research } \\
\text { trends and gaps }\end{array}$ \\
\hline Wang and Burton, 2013 [34] & $107(2006-2011)$ & All & All & All & $\begin{array}{l}\text { Chronological trends, research focus } \\
\text { and characteristics }\end{array}$ \\
\hline Ghanbarzadeh et al., 2014 [35] & $62(1990-2013)$ & Health & $\mathrm{HE}$ and $\mathrm{PE}$ & All & $\begin{array}{l}\text { Characterize and categorize } \\
\text { application areas }\end{array}$ \\
\hline Nussli and Oh, 2014 [36] & 35 (2000-2013) & Teacher Training & $\mathrm{HE}$ and PE & All & $\begin{array}{l}\text { Identification of key components for } \\
\text { effective teacher training }\end{array}$ \\
\hline Reisoğlu et al., 2017 [38] & $167(2000-2015)$ & All & All & All & $\begin{array}{l}\text { Design and research trends, positive and } \\
\text { negative effects }\end{array}$ \\
\hline Pellas et al., 2017 [39] & $50(2000-2016)$ & STEM & $\mathrm{K}-12$ and $\mathrm{HE}$ & All & $\begin{array}{l}\text { Effectiveness, design, affordances and } \\
\text { theoretical underpinnings }\end{array}$ \\
\hline Mantziou et al., 2018 [40] & $205(2003-2016)$ & All & All & All & $\begin{array}{l}\text { Classification of learning affordances } \\
\text { and activities }\end{array}$ \\
\hline Pellas and Mystakidis, 2020 [41] & $28(2006-2019)$ & All & $\mathrm{K}-12$ and $\mathrm{HE}$ & All & $\begin{array}{l}\text { Game-based learning features, instructional } \\
\text { models, effectiveness, benefits } \\
\text { and challenges }\end{array}$ \\
\hline
\end{tabular}

${ }^{1}$ K-12: Primary and Secondary school education; HE: Higher Education; PE: Professional Education; STEM: Science, Technology, Engineering, Mathematics. 
The majority of the previous literature reviews on 3D virtual immersive environments in education had examined multiple levels of education [28,41], including primary, secondary, tertiary, higher, and professional education (PE) and focused mainly on attendancebased applications [30,37]. A minority (only three) had focused on specific fields [35,36,39]. Despite its distinctiveness from school education [42,43], no review was conducted exclusively for finding out about social virtual reality environments' use or virtual worlds in higher education settings [44]. Moreover, there is no systematic examination of SVREs in the distant, online mode of delivery in any level of education. At that time and to the best of our knowledge, relevant studies to examine the effectiveness of SVREs in open and distance mode higher education were not available. The current study aims to address this gap by focusing exclusively on the missing or under-investigated aspects of learning with the use of SVREs.

\section{Materials and Methods}

A systematic literature review was carried out to identify and summarize all the published studies in a thorough research process to analyze the combined three dimensions (affective, cognitive, and social) studied in this research, as previously expressed. The literature review was systematically organized following the Preferred Reporting Items for Systematic Reviews and Meta-Analyses (PRISMA) guidelines [45] as a three-step process involving planning, conducting, and reporting, also suggested by Kitchenham [46]. This is a well-documented and cited systematic review meta-method in software engineering projects. The main research stages and steps of the research methodology that describe our systematic work for this literature review are explained in the next sections. A summary of the review is provided in the PRISMA checklist [45] as a supplementary material (Document S2).

\subsection{Planning Phase}

In the planning phase, we defined and prepared the required instruments and procedures for conducting the literature review. More specifically, the components of the planning phase included the following steps and processes: the rationale and background for this particular review, the research aims and objectives, the research questions, the necessary and most suitable search strategies, identification of the suitable information/data/knowledge bases, the appropriate selection criteria and exact keywords and phrases, the quality assessment procedure, and the data extraction and coding/classification processes. [46]. We elaborate on some of these further with more details.

\subsubsection{Rationale for this Literature Review}

Due to the current coronavirus crisis situation in all levels of education and because of the rapid migration to various virtual and/or distant modes of education, many research initiatives appeared to search exactly that. Thus, the effectiveness of SVREs in open and distance learning in the year 2020 (and most probably in the year 2021) in all levels of education seems to be investigated a lot worldwide and has become a current popular research and development topic. It has been supported that in education, things that were in the agenda to be done within 20 years, were planned, designed, implemented, and realized-willingly or not-within two weeks.

Admittedly, the year 2020, affected by COVID-19, was a transitional stage for elearning and distance education, globally. Having said that and experienced these transitional events, the researchers and authors of this paper evidenced an increase in the transformation of e-learning with or without SVREs and with or without deep and meaningful learning (DML). Presumably, this has been recognized as the (harsh) reality of learning during the continuous COVID-19 pandemic situation worldwide. Our literature review, however, covers the period from the beginning of the Second Life (2003-2004) platform's adoption in e-learning to 2019; this is the pre-coronavirus time. Furthermore, the review only considers e-learning in higher education. 
In addition, the literature review we carried out is not limited only to Second Life in education, as in some previous reviews [31,34]. Other existing virtual worlds designed and realized for learning also fall within our research interest. Such virtual learning worlds are, for example, Open Simulator, Active Worlds, and others.

The authors believe that this research study will eventually be useful for comparing the two states of past and present/future e-learning. It could also be a reference point for comparing and contrasting the previous socio-technical advances and pedagogic effectiveness of SVREs (before 2020) to the enforced, recent advances that had to be urgently adopted for the needs of remote learning and its overall effectiveness.

The related research studies and research reports that appeared during 2020, that is, after our literature review was carried out, are 4 in number [47-50] and they do not holistically examine the combined issues (cognitive, social, and affective) that we emphasize in this study. The main research objective of this study was to address specific gaps and under-researched issues in the research literature and assess the potential of SVREs by mapping their use to the requirements of deep and meaningful e-learning (DML).

Currently, there is a social learning need and socio-economic pressure for preparing the future human workforce for the post-coronavirus era. Predicting and re-assessing the readiness of $\mathrm{HE}$ institutions for this task through the evaluation of outcome-based research has been a motivational force for this study. In so proceeding, the focus has been on the learning experiences, the potential, and the conditions for the achievement of DML, considering and integrating all the affective, cognitive, and social domains. Concurrently, the focus has also been on the rapid changes and enforced technologies in open and distance modes of higher (and not only) education while also having socio-technical factors and virtual reality technology advancements in mind.

Apart from monitoring the changes in the transitional periods before and after 2020, the outcomes of this study are intended to assist educators and practitioners in the collaborative design and implementation of high-quality distance learning programs utilizing SVREs and/or other related information and communication technologies. Finally, education policy makers and institutional leaders could benefit from these research findings since the focus is on the intersection of knowledge organizations' technology adoption policies and social/virtual reality technologies' suitability for learners' needs. Often, and most probably in the future, emergency remote teaching policy plans will prove to be viable by considering their prior use by other e-learners and their (positive or negative) e-learning individual or/and collective experiences, with and/or without technology/skills transfer.

\subsubsection{Research Questions}

To assess the social virtual reality environments' (SVREs) support for deep and meaningful learning (DML) in distance higher education, it was first necessary to search for and evaluate the relevant and related research that has been conducted in this field. At the same time, there was a need to collect evidence on those conditions and instructional methods that have influenced the learning outcomes in SVREs in regard to DML support. Hence, the following research questions were formulated [6]:

1. Which aspects of DML have been studied in the context of distance higher education with the use of SVREs?

2. Which instructional design methods influenced DML support in the use of SVREs in distance higher education?

3. What is the effectiveness of SVREs in distance higher education according to the existing research?

4. What factors influence DML (support) in the context of distance higher education with the use of SVREs?

\subsection{Conducting Phase}

The first activity in this phase was to decide on the search techniques; these were defined to locate objectively relevant primary studies. In the second stage, inclusion and 
exclusion criteria were discussed, defined, and applied. Next, the quality of the initially included studies was scrutinized. The main deliverable of this activity was the initial list of primary studies. The fourth step was data extraction from the included articles. In this last stage, the extracted information was analyzed and synthesized in a suitable manner. The steps are described in more detail in the following section.

\subsubsection{Selection of Data Sources and Search Techniques}

The following techniques were adopted:

1. Electronic searches in the databases Education Resources Information Center (ERIC), EBSCO, Science Direct, Web of Science, IEEE Xplore, and PubMed.

2. Manual searches in relevant journals including Computers and Education, The International Review of Research in Open and Distributed Learning, The British Journal of Educational Technology, The Australasian Journal of Educational Technology, Computers in Human Behavior, and The Internet and Higher Education.

3. Manual searches using the Google Scholar service.

4. Manual branching searches.

For the implemented queries, we used the following terms: social virtual reality, $3 \mathrm{D}$ virtual immersive environments, 3D virtual learning environments (3DVLEs), multiuser virtual environment (MUVE), 3D multi-user learning environments, 3D MULE, immersive worlds, immersive virtual worlds, immersive education, 3D simulation, immersive virtual environments, collaborative virtual environments, immersive learning, metaverse, virtual world, desktop-based virtual reality, desktop virtual world environments, virtual reality, mixed reality, and immersive learning simulations. These were combined with the terms deep learning, meaningful learning, approaches to learning, learning approach, studying approach, approaches to studying, learning strategies, student perceptions, student learning, as well as distance learning, distance education, e-learning, open and distance learning, and open and distance education. After the first round of searches, we performed bidirectional branching searches.

\subsubsection{Selection Criteria}

In the current review, we composed and analyzed the available primary studies published in peer-reviewed journals and conference proceedings that assessed learning in SVREs in HE. We took into account the fact that in the field of computer science, articles published in quality conference proceedings can have the same or a higher impact than published studies in mid-level journals can [51,52].

We defined the following criteria to check the consistency of the studies for inclusion in our review:

1. Empirical studies using SVREs in distance education examining DML.

2. Empirical studies using SVREs in distance education examining learning aspects in at least two of the three DML-associated dimensions (cognitive, social, affective).

3. Studies with samples from HE populations.

4. Studies published in the last 15 years (2004-2019, January), since Second Life started being studied by researchers and before 2020, where the enforced expansion of virtual education happened because of the coronavirus pandemic.

We also used the following criteria to exclude studies:

1. Studies that were not relevant to SVREs (e.g., machine learning, pattern recognition, or 3D visual representation).

2. Studies taking place in $3 \mathrm{D}$ virtual environments without a social element (i.e., experiences where a learner participates individually, without any interaction with teachers or peers).

3. Studies written in languages other than English.

4. Studies that did not undergo the peer-review process.

5. Theoretical studies or studies without evidence or empirical data. 
6. Short studies with insufficient data.

\subsubsection{Searches and the Selection of Studies}

In the initial search, we identified 482 studies that matched the keyword search criteria. After a manual branching search utilizing literature reviews and direct contacts with authors, we identified 83 additional studies for inclusion by repeating the previous process. After judging the title, the abstract, and deploying the set inclusion and exclusion criteria, we identified 216 studies for further consideration. After reading the full manuscripts and assessing their quality, we concluded that there were 33 qualifying empirical studies for inclusion. It is worth noting here that due to the above criteria, interesting studies that have taken place in higher education had to be excluded for a number of reasons:

(i) Took place in a blended mode; partly in a physical location such as a classroom or a college laboratory [53-57];

(ii) Addressed just one domain related to DML [58,59];

(iii) Did not report empirical research findings [60,61].

The overall results of the study's selection procedure are illustrated in Figure 1 as a PRISMA flow diagram.

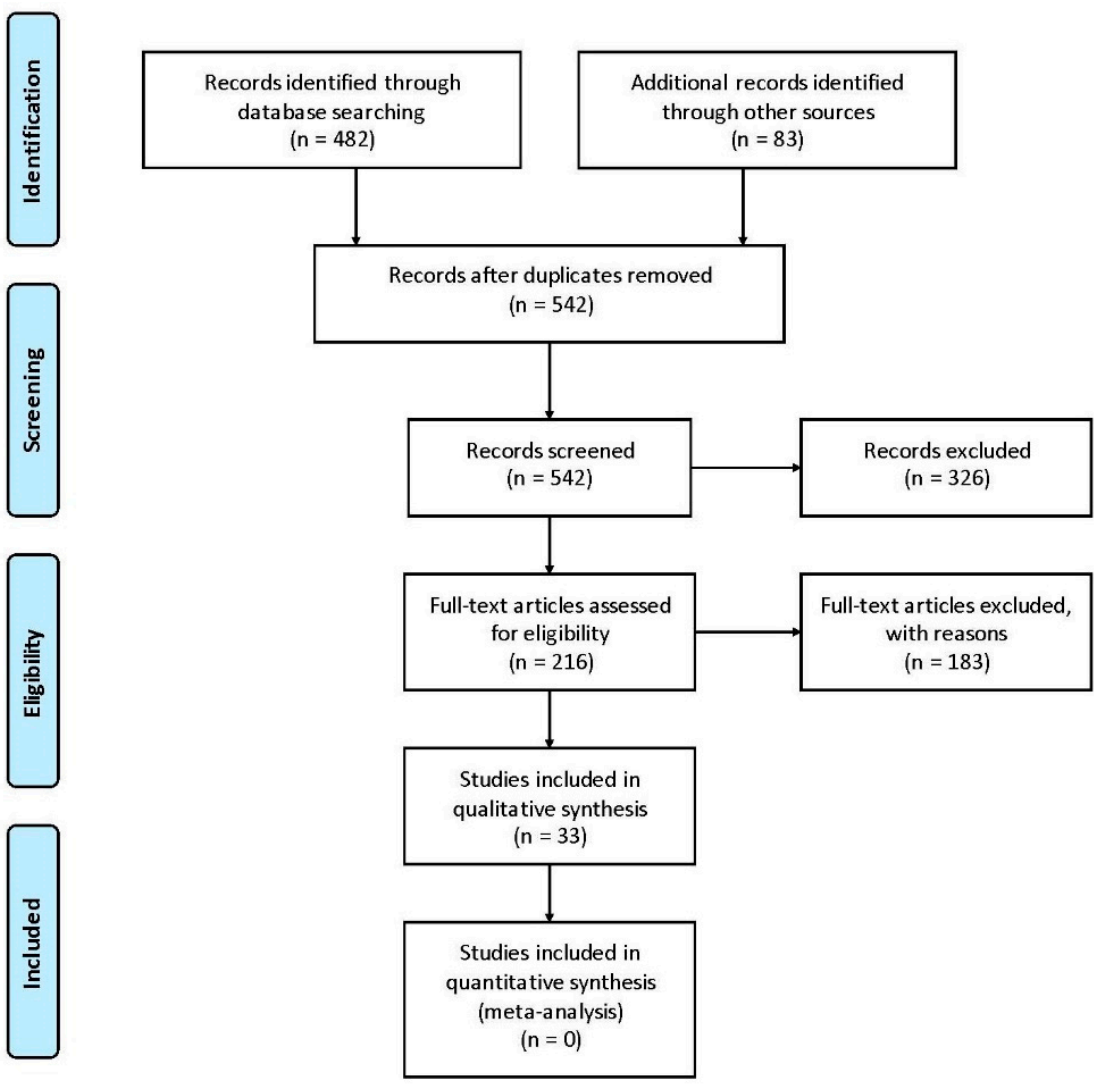

Figure 1. PRISMA flow diagram (from Moher et al. [45]).

\subsubsection{Quality Appraisal}

The thirty-three selected studies were divided into three categories according to their research design: twelve quantitative studies, seven qualitative studies, and fourteen mixed research studies.

The selected quantitative studies were assessed for their validity to test the theoretical hypotheses, establish relationships, or to statistically describe facts [62]. More specifically, we assessed the following issues [63]:

a. The research aim's clarity and logic;

b. Representative sampling; 
c. Control of confounding variables;

d. Research design suitability;

e. The appropriateness of the data analysis methods.

To critically assess the selected qualitative studies, we used the following criteria to determine the validity of the findings [64]:

1. Is the research question clear and adequately substantiated?

2. Is the design appropriate for the research question?

3. Was the method of sampling appropriate for the research question and design?

4. Were data collected and managed systematically?

5. Were data analyzed appropriately?

Studies that followed the mixed method paradigm were appraised by combining the criteria from both of the latter categories.

\subsubsection{Data Extraction and Synthesis}

The basic unit of analysis was each individual article. From each study, we extracted data relevant to our study that were coded to capture the essential information that appears in categories (clusters) related to the formulated research questions. The coding categories are presented in Table 2. The data analysis was conducted through a summary table developed by the researchers and it is provided as an additional material in Document S1. The summary table included the basic information about the publications' characteristics and research design as well as the particular information on the studied and/or researched DML aspects and main findings.

Table 2. Data extraction categories and description.

\begin{tabular}{ll}
\hline \multicolumn{1}{c}{ Category } & \multicolumn{1}{c}{ Description } \\
\hline $\begin{array}{l}\text { Reference } \\
\text { Subject }\end{array}$ & Authors and date of study publication \\
Learning methods & Scientific field or discipline \\
DML domain & Applied teaching or learning methods \\
Research type & DML aspect the study focused on: cognitive, social, or affective \\
Research methods & Applied research paradigm, e.g., qualitative, quantitative, \\
Participants & or mixed \\
Duration & Number of participating learners coded in five categories: less \\
Results & than 10, 10-29, 29-100, 100-499, over 500 \\
Findings & Duration of the learning intervention \\
Implications & The overall conclusion on the effect on learning: positive, \\
& negative, or mixed \\
Cognitive, social, and affective domain DML findings \\
Outcome type & Practice or policy recommendations in accordance with findings \\
& DML outcome the study focused on in each DML domain: \\
& cognitive, social, or affective Examples: \\
& Cognitive outcomes: conceptual, procedural knowledge \\
Social outcomes: collaboration, social presence, connectedness & Affective outcomes: perceptions, motivation, learning benefits \\
ML attributes supported & Meaningful learning attribute the study confirmed or achieved: \\
active, constructive, intentional, authentic, cooperative & The degree of SRVE support for deep and meaningful learning: \\
DML support & high, medium, low, none, negative \\
\hline
\end{tabular}

To tackle RQ1, we extracted the scientific subject, the studied DML domains, the research design attributes, the outcome types, the main findings, and the implications for practice from each paper. The research findings and resultant outcomes were organized for each domain under study: cognitive, social, and affective. The studied cognitive outcomes were conceptual knowledge (CK) and procedural knowledge (PK). The recorded outcomes in the domain of social aspects were qualities and characteristics of collabora- 
tion (COLL), social presence (SPRES), and connectedness to other participants (CONN). The outcomes in the domain of affective issues were learner perceptions about SVREs (PERC), learner motivation (MOT), and learning benefits (LBs) of SVREs.

To answer RQ2, we extracted additional data, namely (i) which of the five attributes of meaningful learning (active, constructive, intentional, authentic, and cooperative) were confirmed or supported by the empirical evidence provided in each study; and (ii) the degree to which SVREs supported DML. The DML support degrees were noted as high, medium, low, none, or negative. To extract data for this category, we used the rubric shown in Table 3. Whenever a study reported a negative result in one domain, this would subsequently lower the total coded DML support degree, taking into account the total aggregate of the results in all domains. In RQ3, we identified and described the many learning effects in each domain. To tackle RQ4, we identified and categorized factors that influence DML and integrated them into a preliminary model.

Table 3. Deep and meaningful learning (DML) support rubric.

\begin{tabular}{ll}
\hline \multicolumn{1}{c}{ Degree of DML Support } & \multicolumn{1}{c}{ Evidence } \\
\hline High & $\begin{array}{l}\text { Explicit reporting of DML and related aspects (e.g., deeper } \\
\text { understanding, skills application, creativity, and critical thinking); } \\
\text { positive reported results in all three DML domains (cognitive, } \\
\text { social, and affective) }\end{array}$ \\
Medium & Positive reported results in two DML domains (aggregated) \\
Low & Positive reported results in one DML domain (aggregated) \\
None & No positive reported results-not applicable \\
Negative & Negative reported results (aggregated) \\
\hline
\end{tabular}

To ensure the reliability of the coded categories, the first author analyzed all studies and the second and third authors each coded half of all included studies. The inter-rater reliability $(r)$ of the studies coded by two authors fluctuated between $75 \%$ and $100 \%$. Any disagreements were discussed until an unanimous decision was reached.

\section{Results}

In the reporting phase, a variety of findings were derived from the extracted data. To facilitate the discussion on DML with SVREs in open and distant education, we compiled the data and reported on the analysis of the included studies to tackle the formulated RQs.

4.1. RQ1: Which Aspects of DML Have been Studied in the Context of Distance Higher Education with the Use of SVREs?

The detailed results are presented in Document S1. The relevant studies were classified as fields of higher education according to the Joint Academic Coding System [65]. The main subject areas under research, as can be seen in Figure 2, were business and economics $(n=5)$ [66,67], computer science $(n=5)$ [68,69], education $(n=5)$ [70,71], languages $(n=5)$ [72,73], science $(n=3)$ [74], and health and medical education $(n=3)$ [75]. Additionally, a chronological publication diagram of these scientific subjects appears in Figure 3.

A peak exists in the period 2010-2013 with twenty-one studies, with notable gaps (with no published studies), for instance, during early years (2006-2008). In terms of the studied DML domains, twenty-nine studies focused on the cognitive domain, twentyeight on the affective domain, and eighteen on the social domain. The most common research design $(n=15)$ was a cognitive and affective domain combination $[67,70,72-84]$. These studies researched the effect of SVREs on student learning and also recorded aspects of the learners' emotional states and perceptions. Nine studies researched all three DML dimensions (cognitive, social, and affective) [27,66,68,69,85-89], while five studies focused on social-cognitive [71,90-93] aspects, and only four studies researched and reported on 
social-affective outcomes [26,94-96]. A tabular representation of those studies in the time limits we included in our study is illustrated in Table 4.

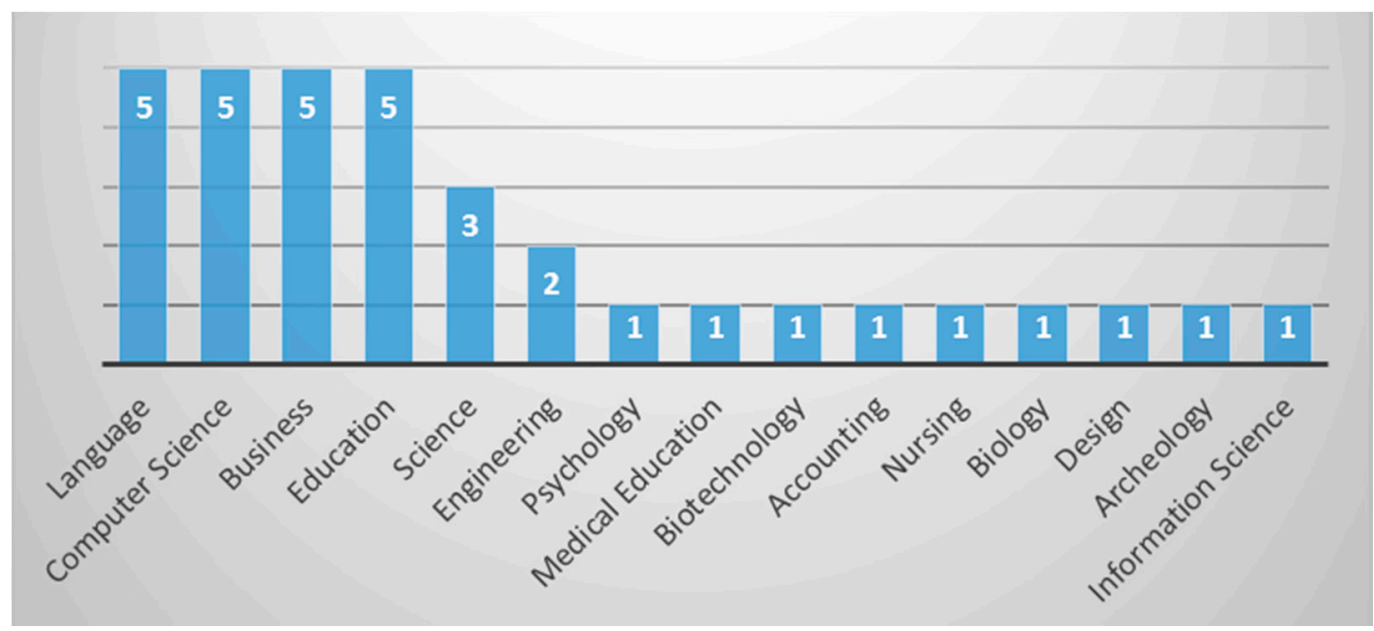

Figure 2. A summary of scientific subjects in distance higher education.

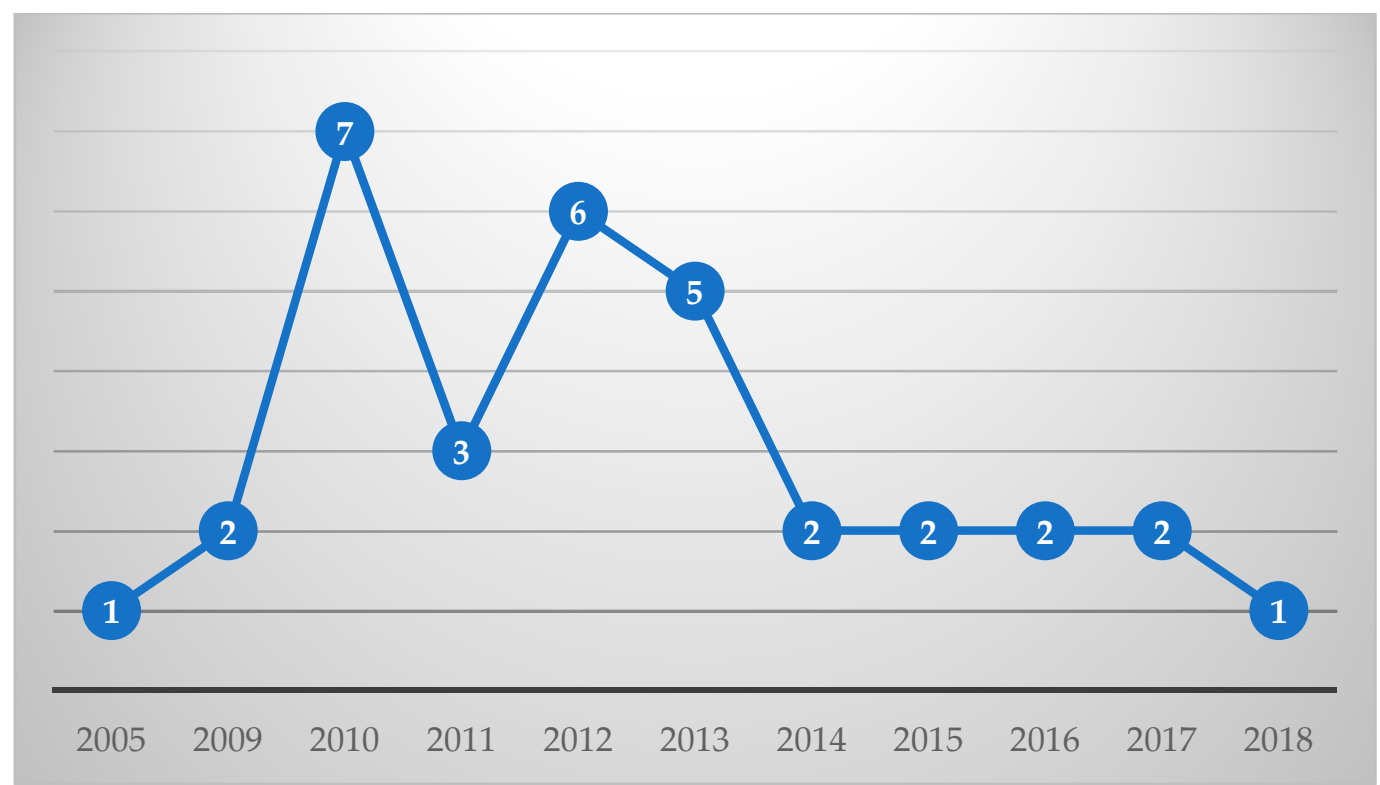

Figure 3. Chronological publication trend from 2005 to 2018.

Table 4. Studied domains (affective, cognitive, and social) across time.

\begin{tabular}{|c|c|c|c|c|c|c|c|c|c|c|c|c|}
\hline Domains & 2005 & 2009 & 2010 & 2011 & 2012 & 2013 & 2014 & 2015 & 2016 & 2017 & 2018 & Total \\
\hline Cognitive-Affective & & & 3 & 1 & 4 & 3 & & 1 & 1 & 2 & & 15 \\
\hline Cognitive, Social, Affective & 1 & 1 & 1 & 1 & 1 & 1 & 1 & 1 & 1 & & & 9 \\
\hline Social-Cognitive & & & 3 & 1 & 1 & & & & & & & 5 \\
\hline Social-Affective & & 1 & & & & 1 & 1 & & & & 1 & 4 \\
\hline Total (Year) & 1 & 2 & 7 & 3 & 6 & 5 & 2 & 2 & 2 & 2 & 1 & 33 \\
\hline
\end{tabular}

Regarding the studied learning outcomes, most articles in the cognitive domain focused on cognitive knowledge $(n=15)[74,78]$, while a significant minority studied procedural knowledge (PK) $(n=8)[77,83]$. The majority of studies with an affective focus researched perceptions (PERC) $(n=25)[79,80,88]$, with motivation (MOT) $(n=5)[72,81]$ being the second most studied construct. In the social domain, the qualities and char- 
acteristics of collaboration (COLL) $(n=7)[89,92,93]$ along with social presence (SPRES) $(n=6)[87,95,96]$ and connectedness $(\mathrm{CONN})(n=3)[71]$ were the primary studied outcomes [6].

4.2. RQ2: Which Instructional Design Methods Influenced DML Support in the Use of SVREs in Distance Higher Education?

The studies used a wide range of learning methods and techniques, with the most prominent being collaborative project-based learning $(n=10)[67,69,80]$, collaborative problembased learning $(n=8)[66,86]$, and collaborative learner-centered learning $(n=6)[81,96]$. Figure 4 is a pictorial representation of the emphasis and use of the aforementioned instructional design methods.

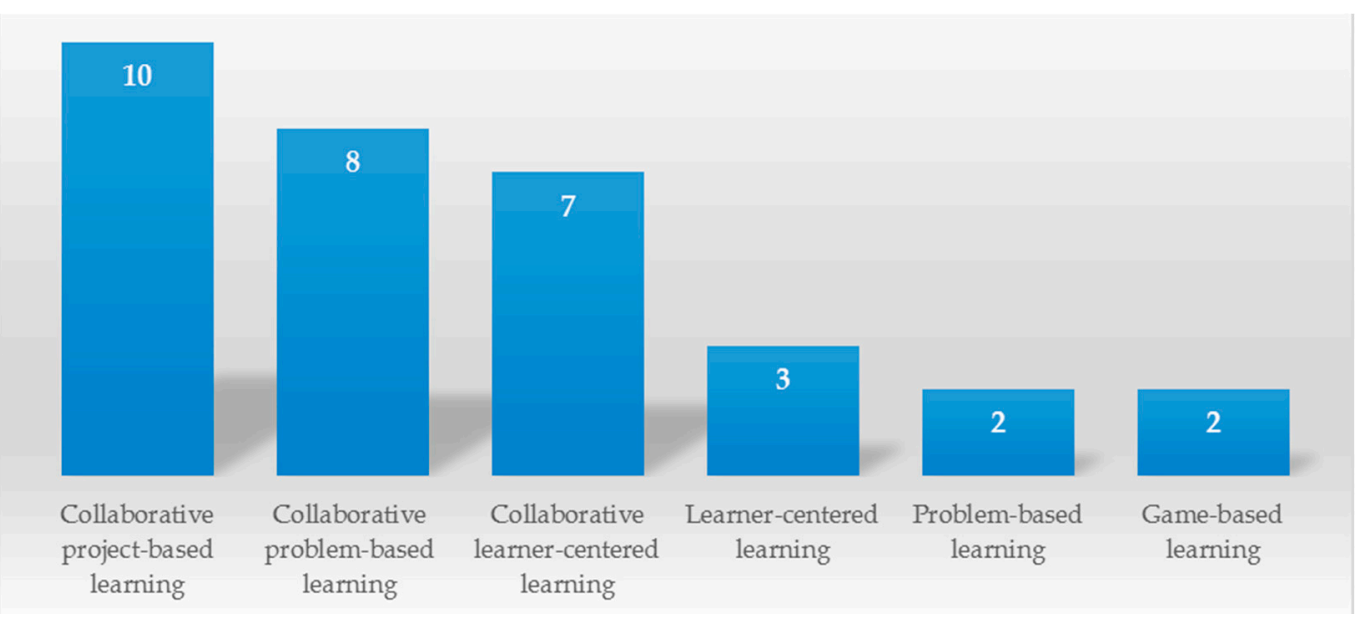

Figure 4. Instructional design methods used in the included social virtual reality environment (SVRE) studies.

When analyzing the level of DML support, we can discern three categories of educational practices in SVREs. There is the top level of innovative practices $(n=8)$ that supports four or five attributes (active, constructive, intentional, authentic, and cooperative) of meaningful learning $[80,83,92,94]$. These studies apply methods such as simulations, problem-based learning, and game-based learning with positive results. Several of these studies observe and report directly on the greater depth of student learning and thinking that takes place [67].

In the middle level, twelve studies deployed elaborated constructionist, constructivist, or socio-constructivist practices that supported three attributes of meaningful learning $[68,78,79]$. For three supported attributes, the most frequently occurring combination included the active, authentic, and cooperative attributes $(n=5)$ [85].

Finally, in the low level, thirteen studies supported two or less attributes of meaningful learning $[73,77,91]$. In these studies, several researchers applied research designs with an emphasis on the control and comparison of specific aspects of the educational experience and not on learning innovation in itself that takes into account the full spectrum of SVRE affordances [6]. However, even these interventions, when well designed and implemented, can lead to deeper levels of thinking and learning [70].

In analyzing and synthesizing the above findings, the recorded degree of SVRE support for DML was overwhelmingly positive, as $85 \%$ of the included studies (28 out of 33) reported high or medium support for DML [6]. It is worth mentioning that most studies that were classified as achieving a medium level of DML support only studied and reported favorable results for two of the three DML domains [75,89]. In other words, it is possible that they also actually achieved positive results in the third missing DML domain, but this fact was not explicitly recorded or reported [6].

Table 5 provides information on the support of DML via SVREs and the number of studies-revealed in this research-that refer to it. 
Table 5. DML support of SVRE studies in higher education (HE).

\begin{tabular}{ccc}
\hline Level of DML Support & Studies & Number of Studies (\%) \\
\hline High & {$[66,67,69-71,77,79,80,85,86]$} & $10(30 \%)$ \\
Medium & {$[26,68,72-76,78,81-84,89-91,94-96]$} & $18(54 \%)$ \\
Low & {$[87,88,93]$} & $3(9 \%)$ \\
None & {$[27,92]$} & $2(6 \%)$ \\
\hline
\end{tabular}

4.3. RQ3: What Is the Effectiveness of SVREs in Distance Higher Education According to the Existing Research?

Overall, 28 studies reported positive results in the cognitive $(n=25)$, social $(n=24)$, and affective $(n=12)$ domains of research focus. Mixed results were recorded by three studies $[26,87,93]$. No studies yielded negative results. Two studies focused on communication modalities [92] and student perceptions [88] and their results cannot be classified as positive or negative.

The most commonly recorded learning effects are summarized in Table 6. In the following, we provide detailed insights about e-learning effectiveness in SVREs in the cognitive, social, and affective dimensions of learning.

Table 6. Learning effects in HE for distant learning with the use of SVREs.

\begin{tabular}{ccc}
\hline Learning Effects & Studies & Number of Studies (\%) \\
\hline Positive impact on learning performance & {$[67,69,70,72,74-76,78,79,81-85,90,91]$} & $16(48 \%)$ \\
Positive impact on perceptions and satisfaction & {$[26,66,69,70,74,75,77,79,82,84,85,89,94,96]$} & $14(42 \%)$ \\
Positive impact on collaboration & {$[26,66,69,71,85,86,89,90,93,94]$} & $10(30 \%)$ \\
Positive impact on motivation & {$[72,73,76,79,82,95]$} & $6(18 \%)$ \\
\hline
\end{tabular}

In particular, the resulted articles researching the cognitive aspects of learning confirmed that distance learning mode interventions in SVREs can improve students' declarative and procedural knowledge [82], knowledge retention [91], higher-order thinking, and problem-solving skills [90]. Furthermore, when learners are active in an SVRE, they become engaged and experience learning gains that improve their performance [78]. Virtual, distant labs in SVREs can effectively support simulated procedural activities to prepare students for professional roles or tasks in the physical world [74,84]. Active inquiry, collaborative workflows, and knowledge-construction activities "assist learners increase the richness and complexity of their cognitive discourse" [88] — clear indicators of DML. Furthermore, the fact that SVREs are pervasive, always-accessible environments facilitates student initiative and informal learning $[79,85,96]$.

The studies examining social aspects of learning concluded that SVRE platforms are effective media for social interactions both among students and between teachers and students [6]. Students were able to collaborate successfully to co-create digital artefacts [67] and complete team-building activities [86]. Additionally, these studies suggested that SVREs could elicit heightened notions of both co-presence and social presence [27]. The increased sense of connection with their digital representations-avatars-captured and sustained the students' attention and made it easier for them to follow conversations [91]. Attention is the first critical step in the cognitive engagement of learners [72]. The use of avatars also helped students to feel companionship and encouraged them to communicate sincerely [95]. Even a few meetings in an SVRE can facilitate the emergence of virtual communities of practice and inquiry [27].

Virtual teams operating in SVREs can engage in meaningful tasks that propel teams to go through the group-development stages and build trust, which is a crucial factor for distributed team performance [94]. Peer interaction and explorative activities are the keys for learning effectiveness [89]. Collaborative problem solving and collaborative observation had higher effectiveness in cultivating sustainable intrinsic motivation and distant team performance than teacher-centered approaches to instruction [81,88]. Okita et al. [81] 
concluded that avatar-mediated tutoring and the associated recursive feedback observation led to significant learning gains. However, establishing a social presence is not sufficient in itself for the achievement of cognitive learning goals [85]. In any case, SVREs can enhance peer collaboration in e-learning either as stand-alone platforms [89] or when combined in blended environments with other collaborative tools or asynchronous learning platforms [79]. Effective peer collaboration and social interaction evoke interest and motivation [88].

Manuscripts studying affective aspects in education confirmed that engagement, motivation, and academic achievement depend heavily on students' perceptions and emotions [80]. Remote participants were more comfortable and relaxed in an SVRE in comparison to a physical space that was often associated with stress [85]. Online learners that had demonstrated feelings of reticence and nervousness felt empowered to participate freely in an avatar-mediated SVRE [76], as active, scaffolding activities in SVREs can enhance learners' self-efficacy [75]. Activating positive emotions and feelings of joy significantly affects students' academic achievement [88]; when learners enjoy and appreciate the value of a task in a virtual environment, they tend to learn more, engage in richer interactions, and not only perform better in formal assessments [80], but also tend to gain a deeper, more profound knowledge in comparison to attendance-based teaching models [85].

Learners' motivation remains consistently high in longer e-courses employing SVREs [76]. Higher levels of motivation and engagement in open and distance learning with SVREs can lead to lower attrition rates [66,79]. Effective learning experiences in SVREs can, potentially, elicit a sense of flow [88], the pleasurable psychological state of increased immersion, and an energized focus while actively engaged in a meaningful experience [29]. The joy of completing a difficult but personally significant task evoked feelings of euphoria, as demonstrated in the following comment: "Sometimes it was frustrating but the sense of satisfaction when the SLurtle built a perfect house or a beautiful tree was worth all of the frustration" [77].

\subsection{RQ4: What Factors Influence DML (Support) in the Context of Distance Higher Education with the Use of SVREs?}

To tackle this question, we identified and distinguished the classes of factors and antecedents that mediate DML with SVREs in distance education settings and integrated them into a comprehensive model [6]. By analyzing the reviewed studies, we classified the conditions and factors across two dimensions: (i) according to the acting entity or person and (ii) in relation to the time of the educational intervention. First, there are (a) individual learner factors [93] and (b) contextual factors related to technology, learning design [71] and implementation, and the institutional environment [84].

These categories of factors can be mapped before, during, and after learning. All factor categories compose a Blended Model for Deep and Meaningful E-learning in Social Virtual Reality Environments that is depicted in Figure 5. The model we constructed and present next incorporates the essential interactions between teachers, students, and content in prior models for DML [97] and a constructive alignment for quality learning experiences [98].

First, the layer of student pre-learning factors includes their inherent characteristics [71], perceptions [96], and relevant technical skills [88]. The learner characteristics encompass personality attributes such as cognitive ability, values, beliefs, and behavior orientation (e.g., introverted vs. extroverted personality). Perceptions contain situational attitudes toward a specific learning intervention. They include conceptions of studying and learning, interest, self-efficacy, and the motivation to learn [81]. These variables are not static and are connected to the emotions experienced during learning; design and implementation can enhance or diminish learners' interest in education and motivation for DML. What is equally impactful in e-learning is the level of technical competence related to the used systems. Several studies have confirmed that this factor can obstruct learning when neglected $[75,95]$. In other words, prior to the learning process, teachers should confirm the adequacy of the learners' skills and provide ample opportunities for them to 
familiarize themselves with new tools and platforms so as to ensure that "the technology does not get in the way of learning."

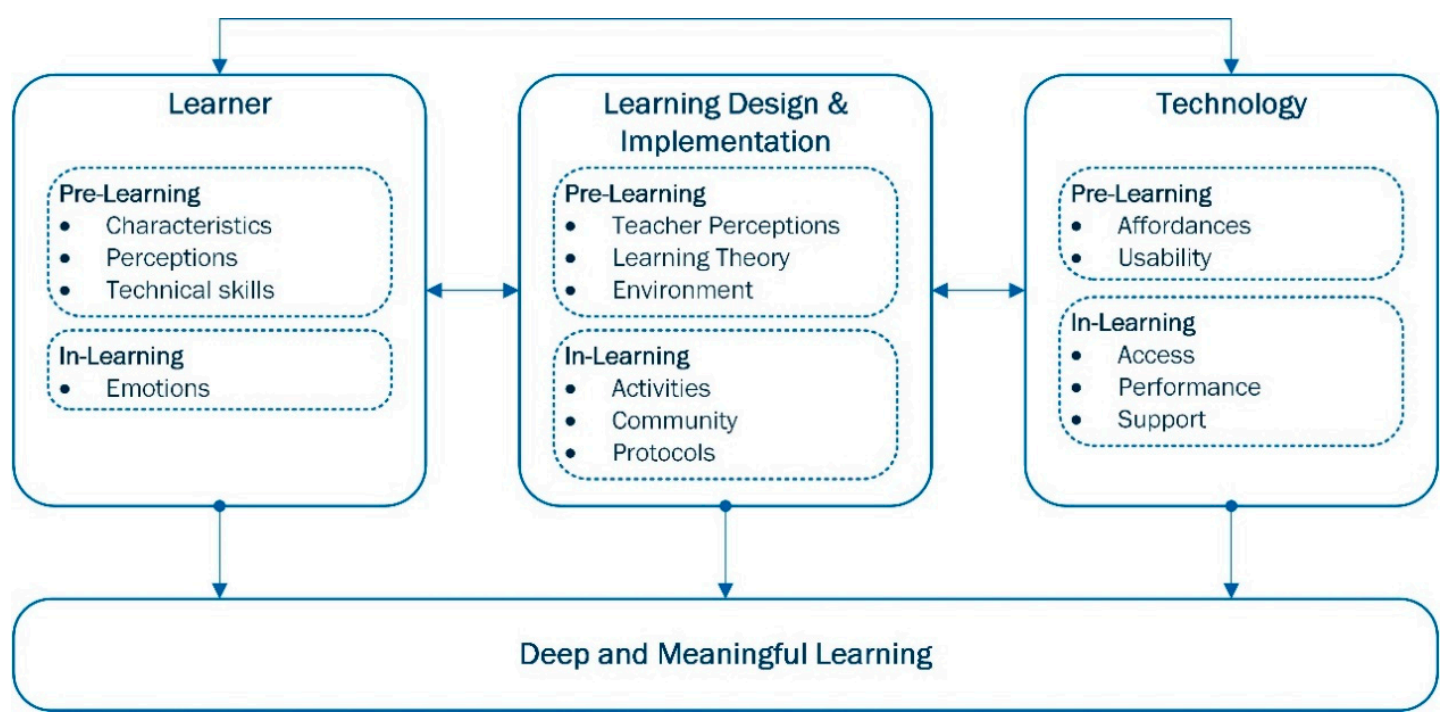

Figure 5. Blended Model for Deep and Meaningful E-learning in Social Virtual Reality Environments.

In regard to the classes of technology and of learning design and implementation in a computer-mediated system such as an immersive virtual world, the dynamic has been partly described by Duncan, Miller, and Jiang [33]. Technological systems' affordances and level of usability by non-technical users define the constraints of what is possible within the platform $[27,68]$. In addition, during learning, user access, the performance robustness, and the existence or lack of user support are decisive enabling or inhibiting factors for DML $[79,91]$.

Next, in the category of learning design and implementation, teacher perceptions and the adoption of a certain learning theory, philosophy, or pedagogic framework-or lack thereof-dictate the functional and aesthetic decisions on the characteristics of the 3D learning environment prior to learning $[77,83,86]$. In turn, these enlighten the teaching and learning activities in the pursuit of specific learning outcomes [67,71].

Two additional, interconnected factors during the in-learning phase include the establishment and maintenance of a sense of social presence in a community of inquiry or practice where learners can build and navigate personal connections $[27,66,96]$, and the establishment of clear protocols of collaboration and communication, especially for less structured environments and activities [88,94].

Cognitive overload as a result of the limited capacity of the human mind is a potential threat for distance learning quality, especially on rich, open, interactive SVRE platforms, where learning takes place in a rich digital space with multimodal stimuli [6]. In two studies of this literature review, one technology affordance and one learning design decision-the addition of communication through voice in SVREs [92] and a structured collaborative environment in comparison to an unstructured one [68], respectively-led to positive effects on learning by decreasing cognitive load [6].

\section{Discussion}

Several studies that examined the cognitive dimension of learning applications in social VR differentiate descriptive or declarative [92] from procedural knowledge [85], while others examine retention [91], skill acquisition [77], and comprehension [67]. Reported success for any of these outcomes and measures, however, does not equate to or automatically result in deep and meaningful learning (DML). Virtual worlds have been found to be suitable for knowledge-based, abilities-based, or skill-based learning outcome achievement [37]. 
Nevertheless, DML has not been widely researched in the context of distance education with the use of SVREs. In this context, our research yielded just one study with an explicit focus on DML [86]. There are several factors that could explain this phenomenon. First, the topic of DML in itself is quite complex and not fully developed. Evaluating deep learning with validity and reliability in any educational settings and social conditions can be very challenging. For instance, one common instrument to estimate deep learning is a questionnaire. Self-reporting certainly has its limitations [13]. Furthermore, actual student behavior and performance could differ from their self-perceptions [10]. The assessment of meaningful learning should aim at higher-order processes and can, therefore, be daunting.

Three-dimensional virtual learning environments (SVREs) can serve multiple purposes within an e-learning program [99]. In one study, trainees participating in desktop virtual reality experiences achieved superior outcomes in declarative knowledge, procedural knowledge, and knowledge retention than the control groups did [29]. The element of immersion in a situation, a problem, or a professional competence allows educators to re-orient the depth of learning outcomes for online educational experiences from learning about a subject to learning by doing and by emulating a role, and this enables deep conceptual and procedural knowledge to be built of a discipline, which is far superior to a superficial declarative knowledge about the content area [100].

Elaborating on the importance of teacher perceptions and learning theory in relation to technical aspects of the learning environment, as Mikropoulos and Natsis [30] point out (p. 774), "carefully designed learning activities are more important than an exotic interface that contributes to intuitive interaction." One general classification of learning activities in SVREs lists the relevant activities as follows: content creation, content exploration and interaction with the content, social interaction, gaming, and participation in representations of real-life events and situations [40]. Indeed, a meta-analysis of desktop-based virtual reality instruction found no difference between high and low research design quality, which is an indicator of the robustness of its benefits for learning [37]. Moreover, a high degree of sensed presence in SVREs correlates with learning performance [30]. More importantly, this affordance of the medium and the induced sense of presence were not influenced by the design of the educational environment [40].

Learning activities in SVREs can be combined with traditional instructional strategies in a meaningful way; that is, learning achievement increased when simulations were utilized as supplementary practice than when they were planned as autonomous experiences [37]. SVREs can be used as platforms to provide authentic, realistic, cognitively challenging experiences in engaging, motivating environments for open-ended social, collaborative interactions and for intentional, purposeful, self-directed learning. In other words, they can embrace all three DML dimensions: mind, emotions, and a community for mastery, autonomy, and connectedness [101].

Learning in a 3D virtual environment can elicit a spectrum of possible emotional states, both positive and negative [88]. Examples of negative emotions are frustration, caution, distraction, fear of failure, boredom, and amotivation, while positive emotional states include attention, intrinsic motivation, flow, self-efficacy, self-esteem, self-confidence, enjoyment, and satisfaction. In short, SVREs can facilitate superior self-expression and formal and informal genuine peer communication and they can enable active, authentic, motivating experiences. Makransky and Petersen [102] found that effective learning in desktop virtual reality simulations involves affective factors and students' beliefs.

Game-based experiences in SVREs have been effective in eliciting intrinsic motivation and student satisfaction in distance education [72]. Students in game-based or/and playful environments were intrinsically motivated, working to solve problems, tasks, and challenges $[78,79]$. Game-based curriculum studies in blended K-12 settings have demonstrated the superiority of gamification experiences in terms of learning gains and complex skill construction in comparison to teacher-centered methods $[103,104]$. Simulated, game-informed roleplay experiences are perceived to be free from the fear of failure [72], as failing in a virtual environment does not carry harmful consequences, and repetitive practice is a viable 
path toward mastery [74]. These effects are corroborated by recent related SVRE publications in terms of student engagement through gamification [50], deeper learning through game- and problem-based learning [49], and learning performance through embodied pedagogical agents [48] in the context of education 3.0 systems [47].

\subsection{Recommendations for E-Learning Practice}

Attendance-based education is, potentially, a privileged context for learning, as educators can employ any teaching method and medium within institutional and organizational constraints. Distance teaching in 3D virtual immersive reality "appears to require yet another set of skills in addition to the skills required for teaching in 2D environments" [36]. By combining and perusing the outcomes from the included studies, we further propose the following recommendations for DML in SVREs: meaningful contexts, purposeful activation, learner agency, intrinsic emotional engagement, holistic social integration, and $360^{\circ}$ obstacle removal.

Technology alone cannot cause learning to happen but its affordances can make specific activities possible where learning takes place [105] within usable contexts. Learning environments and activities in an SVRE have to be designed in an appropriate context, aligned with the program's learning outcomes and the learners' goals [36]. This context can be authentic, realistic, or completely fictional, but should be cognitively related to the intended learning outcomes (e.g., through metaphors or storytelling) [106]. It should serve a specific need and purpose that learners will embrace voluntarily to be active and work toward a main educational goal, a purposeful target, or learning-centered challenge. Active learning enhances metacognition skills and helps students to build mental models of the studied discipline [29]. Therefore, they must be emotionally engaged. Being in the SVRE should be a positive, desirable experience, even when it has to do with obligatory study duties and learning tasks such as a professional training. The latter is often an obligation and perhaps not a knowledge priority in the learners' point of view. Educators should be instrumental in cultivating the ethos of the shared environments toward trust building [94]. Learners, on the other hand, should be encouraged to exercise agency, with the freedom to make choices in their engagement with the content, objects, the artificial intelligence entities such as non-player characters in the environment, and especially with teachers and peers. Exercising control over their experience is beneficial for students' learning [30].

The SVRE should not merely be a "virtual classroom" where course meetings take place. The different spaces could be the students' locker rooms, cafés, workshops, or alternative places for online social formal and informal peer interactions $[79,87,96]$, but not to the detriment of learning. Creating the conditions for students to discuss and exchange their opinions enables them to explore and encourages an attitude of inquiry [27]. Finally, at the operational level, one prerequisite is that all technological, psychological, or other obstacles should be removed meticulously, creating comprehensive, $360^{\circ}$, friction-free experiences.

As already stressed, a recommended plan is to provide users with sufficient opportunities with supportive personnel in onboarding and experimentation sessions so that they can become familiar with the available SVRE platform [6]. One way to combine all these attributes is by using game-informed approaches or other instructional methods that intrinsically motivate learners to assert cognitive effort.

In the long run and witnessing the rapid developments in virtual reality (VR) and the significant rise in usage of this technology in other regions of the globe, e.g. [107], the stakeholders of higher education should establish projects to pro-actively address the evolving digital skills gaps that learners and learning agents are increasingly facing.

\subsection{Limitations and Ethical Considerations}

One study cannot include everything that exists. This study also has some limitations of which the reader should be aware. First, this study focused on social, not individual, aspects of e-learning taking place in 3D virtual environments. That is, the focus has been on studies which have used multi-user not single-user mode. Social interaction is a vital 
affordance of SVREs. Second, this study reviewed published empirical e-learning studies which have been conducted between 2004 and 2019. That is, the period from the launch of Second Life to the time before the coronavirus pandemic erupted. There are studies that were conducted before 2004 and during the COVID-19 pandemic, but this study focused on the maturing era of SVREs, not the early years or the coronavirus pandemic era. Third, this study included only published studies which were written in English. There are many studies conducted in other languages, but they were excluded since we assumed that the reader might not have the necessary language skills to read those studies too. Fourth, this study focused on the higher education context. For this reason, primary and secondary education contexts were not included in this study. Hence, this study focused on adult learners rather than children as learners. Fifth, this study paid attention to the formal learning rather than informal learning context. Sixth, this study focused on humans' deep and meaningful learning rather than machines' deep learning, which is actively studied by artificial intelligent researchers. Seventh, concerning humans' deep and meaningful learning, this study paid attention to the published studies which handled at least two of the following three aspects of deep and meaningful learning: cognitive, social, or affective. Therefore, those studies that focused on only one of the aspects were excluded from this study.

Every study has some ethical issues which both the authors and the readers should be aware of. First, there might be some ethical issues arising from perceived or real conflicts of interest such as financial interests, which may influence the findings of systematic literature reviews. This study was not a sponsored systematic literature review. In so being, no external funding source influenced the findings. Second, there might be some ethical issues concerning whose voice is heard (more). That is, less influential and marginalized groups might have difficulties to be heard. This study, for example, did not focus only on the Second Life studies, which are plenty, but also included other voices. Third, there might be some ethical issues concerning how appropriately the relevant published studies were searched and selected-more explicitly, how well the researchers managed to consider the impact of potential search biases such as availability bias, database bias, citation bias, country bias, familiarity bias, language bias, and multiple publication biases. In addition, how well the researchers managed to consider the impact of potential publication biases such as funding bias, methodological bias, and outcome bias is also worth mentioning as studies with certain methodological orientations might be more likely to be funded. Studies with a large sample size might be more likely to be published. Studies with significant positive effects might be more likely to be cited. In this study, we included only high-quality published research that has undergone the peer-review process. In so doing, we excluded, for example, potential government reports, published and unpublished, as well as book chapters. We designed a search strategy which gave us access to the most relevant primary research from a variety of sources without excluding diverse contextual viewpoints. We held appropriate transparency to the reader during the whole review process.

In this research work, we reviewed published empirical e-learning studies taking place in 3D virtual environments that feature social elements. Social interaction is a vital affordance of SVREs that corresponds to the respective dimension of deep and meaningful learning. However, there are many studies that effectively use desktop-based virtual reality environments or virtual worlds in single-user mode. Furthermore, deep learners exhibit an intrinsic interest in understanding the studied discipline [10]. Despite encouraging results on DML support, no definite conclusions can be drawn due to the fact that DML is not the research focus in the reviewed published works of this study.

Throughout this research study, we did not focus on issues of an ethical and philosophical nature. Instead, we chose to put emphasis on the examination of those features of virtual learning environments that relate to deep and meaningful learning. There are, however, a number of issues such as privacy, security, and identity management that have gained recent research interest in the fields of applied ethics and other branches of philosophy such as aesthetics and cultural semiotics. Many researchers take either a 
positive or a skeptical approach towards these issues, whilst it seems that a pragmatic point of view tends to balance the interaction of pedagogy and utilitarianism. Privacy and security concerns often rise as general social awareness indications for learners' interactions in diverse geographical and cultural contexts [108]. Furthermore, Metzinger (2018) [109] explores promising points of collaboration between virtual reality and philosophy.

\subsection{Directions for Further Research}

The research methodology and most of the preliminary findings of this research study are further exposed in detail along with other results and commentary as part of the doctoral thesis of the first author [6]. Therein, a future roadmap is also outlined based on the use and usefulness of the findings for various stakeholders involved in the e-learning process.

Deep and meaningful learning (DML) could be considered as a theoretical framework that could be developed further to meet the demands of a knowledge-intensive economy and rapidly digitized society where open and distance learning is an integral, vibrant field and practice. As lifelong e-learning will be an ongoing necessity and core activity for the majority of the working population throughout their career, additional studies should be carried out on how technology-enhanced learning and, specifically, social VR can assist trainers and knowledge providers to handle and accommodate emotional and social issues in adult education, professional training, and especially lifelong e-learning courses.

Future longitudinal studies could be the vehicle to reveal more affective, cognitive, and social as well as technical issues that were under investigation in our study. So far, in the majority of the examined cases, there was not a single longitudinal study to handle this aspect. The longest period used by the researchers was 20 weeks only and only in one study [86]. For instance, the duration of the data collection samples taken for investigation by 9 out of 33 researchers was one day. Another 13 researcher groups used samples taken between 1 and 8 weeks. Hence, longer time periods, following the examples of Keskitalo et al. [86], O'Connor [71], and Mystakidis et al. [79], could produce more reliable information and potentially more valid knowledge about various topics under investigation in virtual education rather than using only a cross-sectional study design.

Notably, the majority of the examined studies in our literature review were quantitative (12) and mixed-method research (14), out of 33 studies. In order to gain a new perspective and open up new research avenues in studying SVREs in education, researchers should also consider qualitative research studies in the future. New knowledge could also be obtained by the use of other research data collection and analysis methods than questionnaires, interviews, and pre-/post-tests. New ways of researching could be longlasting deep interviews, focus groups, and narrative forms of learners' diaries or/and video (and self-video) recordings of the learning process. Furthermore, systematic syntheses of empirical studies utilizing SVREs in distance school (K-12) education are also missing.

A related issue in the future research agenda is how one could quantitatively measure the quality of DML and the process and outcome effectiveness in simulations, games, roleplays, and other interventions in SVREs with reliable metrics. Most experimental studies use pre-test/post-test measures to assess learning. However, such a static assessment format is questionable for complex learning environments and is not suitable to reliably evaluate deep learning [92]. New evidence-centered, natural, authentic, forward-looking assessment models are needed to assess higher-order skills and deep learning.

There is an educational and social need to further research the effects of immersion, identity management, and privacy in virtual learning environments since these can hinder or facilitate deep and meaningful learning. This socio-technical and ethical issue does not stand alone in online educational environments. Other socio-technical, pedagogical, and ethical problems have been, for a long time, recognized as notable gaps and limitations in the research and development of open and distance learning and virtual higher education [110-113]. All of these have only recently been more obvious because of the massive migration to e-learning spaces [17,110] during the year 2020. For instance, user protection 
and user privacy are only two of the nine ethical challenges in virtual reality game environments [114] and the lack of specialized cyber security knowledge of students in higher education institutes worldwide [112] exacerbates the problem. Suitable mechanisms to support and guarantee the confidentiality of e-course participants should be co-designed in stakeholders' collaboration and developed for the needs of future e-learners.

\section{Conclusions}

Our research study revealed that SVREs are being used consistently across time in distance learning in HE for a wide array of subjects. SVREs effectively support learnercentered instructional e-learning approaches such as project- and collaborative problembased learning. These methods appear to be effective towards DML in HE. Overall, 54\% of the included studies $(n=18)$ recorded positive learning effects in two of the three domains associated with DML; cognitive, social, or affective. Ten additional studies (30\%) reported positive results in all three domains. The most common observed learning effects were performance gains, high levels of satisfaction, collaboration, and motivation. Analyzing these studies, we aggregated a model of fifteen critical factors for DML related to learners, design, and technology.

The findings of this systematic literature review shed light on an era of slow adoption and use of distance learning through virtual learning environments. These research outcomes, in general, enhance understanding of the status of open and distance learning in higher education. The study and its outcomes also provide a particular focal point to the use of virtual learning environments in providing contributions to deep and meaningful learning (DML).

From the theoretical and practical points of view, new guidelines and recommendations based on the literature review findings could support instructional design and improve teaching and learning practices across multiple subjects.

Admittedly, early researchers of social virtual reality learning environments tend to have a positive and optimistic stance towards technology acceptance and benefits for the effectiveness of particular e-learning methods and tools. This tendency often overshadows ethical considerations and potential dangers in the short and long run. For example, problematic situations that easily arise from the use of SVREs such as online privacy and cyber security, cyber bullying, group-thinking, addiction, and many other psycho-somatic and cyber communication consequences are hardly mentioned, if at all. The reason for this neglect might not just be the well-known phenomenon of the subjectivity of the researcherit could possibly be the general desire to reach successful e-learning outcomes in order to prove the use of e-learning environments as valuable for all stakeholders.

E-learning stakeholders (e.g., learners, instructors, educational policy makers, academic leaders, and VR developers) can use the resulted socio-technical and pedagogic Blended Model for Deep and Meaningful E-learning in Social Virtual Reality Environments to identify and take into account all the interlinked factor categories that include individual, design-related, implementational, technological, and socio-technical aspects that mediate DML.

From practical and historical points of view, the empirical data in this review provide valuable chronological information regarding DML in different eras of distance education. Thus, this review also contributes to the field by summarizing good teaching and learning practices worldwide and by providing analytical insights. In that sense, the review facilitates a culture shift towards active and personal learning in distance education by adopting learner-centered strategies. This can be a vehicle for a paradigm shift if it is combined with the required suitable guidance by a "change agent of learning" online or offline. The latter, that is an online/offline learning change agent, was lacking and sometimes proved to be one of the most critical aspects of the success of e-learning before and during the coronavirus crisis in distance mode learning. This particular learning item could be conceptualized and realized as an actual human component or learning interface item. In regard to social virtual learning environments, there seem to be a few under-researched 
topics increasing in popularity right now under the lens of pedagogic research projects internationally $[6,17,48]$.

Moreover, this literature review contributes to the exposure and understanding of the virtual reality environment development trends and usage before the year 2020, when a rapid growth and adoption of e-learning practices came as the result of the worldwide COVID-19 pandemic. The findings could also be used from a historical point of view to compare and contrast past and current/future trends in e-learning in higher education institutes worldwide. Hopefully, in the future, more systematic literature reviews will be conducted on social virtual learning environments appearing before and after the year 2019 in order for future researchers to be able to utilize various different or similar methodological viewpoints and research results.

Apparently and potentially, strongly and collaboratively built SVREs can support DML by combining a variety of student-centered learning methods grounded on socioconstructivist principles that engage students on the social, cognitive, and emotional levels. Online educators must pay special attention to the taught content while equal emphasis is warranted also on the social and affective learning mechanisms. One realization strategy is to enhance student motivation through social interaction using collaborative teaching techniques such as problem-, project-, inquiry-, or game-based learning.

As social virtual reality and communication technologies already started to revolutionize how learning can happen in the new post-coronavirus era, change in learning is certain. Learning is not static; it is dynamic. Unsurprisingly, various motivational forces drive the changes and adaptation to e-learning in a speedy way. In parallel, there is a socio-technical need for further research and development in the critical mind, with care and wisdom to create equal opportunities for future online learning settings in an uncertain offline world.

Supplementary Materials: The following are available online at https:/ / www.mdpi.com/2076-341 7/11/5/2412/s1, Document S1: Summary of articles included in the review, Document S2: PRISMA 2009 Checklist.

Author Contributions: Conceptualization, S.M.; methodology, S.M.; software, S.M.; validation, E.B. and J.-P.V.; formal analysis, S.M., E.B. and J.-P.V.; investigation, S.M.; resources, S.M. and J.-P.V.; data curation, S.M.; writing-original draft preparation, S.M.; writing-review and editing, E.B. and J.-P.V.; visualization, S.M.; supervision, S.M.; project administration, S.M. All authors have read and agreed to the published version of the manuscript.

Funding: This research received no external funding.

Institutional Review Board Statement: Not applicable.

Informed Consent Statement: Not applicable.

Conflicts of Interest: The authors declare no conflict of interest.

\section{References}

1. Craik, F.I.M.; Lockhart, R.S. Levels of processing: A framework for memory research. J. Verbal Learn. Verbal Behav. 1972, 11, 671-684. [CrossRef]

2. Hartnett, M. The Importance of Motivation in Online Learning. In Motivation in Online Education; Springer: Singapore, 2016; pp. 5-32. ISBN 978-981-10-0700-2.

3. Juutinen, S.; Saariluoma, P. Emotional obstacles for e-learning-A user psychological analysis. Eur. J. Open Distance E-Learn. 2010, 1,7 .

4. Illeris, K. An overview of the history of learning theory. Eur. J. Educ. 2018, 53, 86-101. [CrossRef]

5. Marton, F.; Säljö, R. On Qualitative Differences in Learning-II Outcome as a Function of the Learner's Conception of the Task. Br. J. Educ. Psychol. 1976, 46, 115-127. [CrossRef]

6. Mystakidis, S. Motivation Enhanced Deep and Meaningful Learning with Social Virtual Reality. Ph.D. Thesis, University of Jyväskylä, Jyväskylä, Finland, 2019.

7. Ohlsson, S. Deep Learning: How the Mind Overrides Experience; Cambridge University Press: Cambridge, UK, 2011; ISBN 9781139496759.

8. Hay, D.B.; Kehoe, C.; Miquel, M.E.; Hatzipanagos, S.; Kinchin, I.M.; Keevil, S.F.; Lygo-Baker, S. Measuring the quality of e-learning. Br. J. Educ. Technol. 2008, 39, 1037-1056. [CrossRef] 
9. Valtanen, J.; Berki, E.; Kampylis, P.; Theodorakopoulou, M. Manifold Thinking And Distributed Problem-Based Learning: Is There Potential For ICT Support? In Proceedings of the e-Learning'08 Conference, Amsterdam, The Netherlands, 22-25 July 2008; Volume I, pp. 145-152.

10. Dolmans, D.H.J.M.; Loyens, S.M.M.; Marcq, H.; Gijbels, D. Deep and surface learning in problem-based learning: A review of the literature. Adv. Health Sci. Educ. 2016, 21, 1087-1112. [CrossRef]

11. Ausubel, D.P. In Defense of Verbal Learning. Educ. Theory 1961, 11, 15-25. [CrossRef]

12. Howland, J.L.; Jonassen, D.H.; Marra, R.M. Meaningful Learning with Technology, 4th ed.; Pearson: New York, NY, USA, 2011; ISBN 9780132565585.

13. Rourke, L.; Kanuka, H. Learning in Communities of Inquiry: A Review of the Literature. J. Distance Educ. 2009, $23,19-48$.

14. Fink, L.D. Creating Significant Learning Experiences: An Integrated Approach to Designing College Courses; Jossey-Bass: San Francisco, CA, USA, 2003.

15. Garrison, D.R.; Anderson, T.; Archer, W. Critical Inquiry in a Text-Based Environment: Computer Conferencing in Higher Education. Internet High. Educ. 1999, 2, 87-105. [CrossRef]

16. Mystakidis, S.; Berki, E.; Valtanen, J. The Patras Blended Strategy Model for Deep and Meaningful Learning in Quality Life-Long Distance Education. Electron. J. e-Learn. 2019, 17, 66-78. [CrossRef]

17. Georgiadou, E.; Berki, E.; Valtanen, J.; Siakas, K.; Rahanu, H.; Edwards, A.; Paltalidis, N.; Agouropoulos, A.; Hatzipanagos, S.; Panov, Y. Challenges of Rapid Migration to Fully Virtual Education in the Age of the Coronavirus Pandemic: Experiences from Across the World. In Proceedings of the 25th Annual INSPIRE Conference, Online, 16 July 2020; Uhomoibhi, J., Dewar, E., Georgiadou, E., Linecar, P., Marchbank, P., Ross, M., Staples, G., Eds.; pp. 253-333.

18. Schultz, R.B.; Demers, M.N. Transitioning from Emergency Remote Learning to Deep Online Learning Experiences in Geography Education. J. Geogr. 2020, 119, 142-146. [CrossRef]

19. Bawa, D.P. Learning in the age of SARS-COV-2: A quantitative study of learners' performance in the age of emergency remote teaching. Comput. Educ. Open 2020, 1, 100016. [CrossRef]

20. Schiefele, U. Interest, Learning, and Motivation. Educ. Psychol. 1991, 26, 299-323. [CrossRef]

21. Covington, M.V.; Müeller, K.J. Intrinsic Versus Extrinsic Motivation: An Approach/Avoidance Reformulation. Educ. Psychol. Rev. 2001, 13, 157-176. [CrossRef]

22. Rothes, A.; Lemos, M.S.; Gonçalves, T. Motivational Profiles of Adult Learners. Adult Educ. Q. 2017, 67, 3-29. [CrossRef]

23. Paulus, T.; Scherff, L. Can Anyone Offer any Words of Encouragement?" Online Dialogue as a Support Mechanism for Preservice Teachers. J. Technol. Teach. Educ. 2008, 16, 113-136.

24. Mimirinis, M.; Bhattacharya, M. Design of Virtual Learning Environments for Deep Learning. J. Interact. Learn. Res. 2007, 18, 55-64.

25. Yilmaz, R.M.; Topu, F.B.; Goktas, Y.; Coban, M. Social presence and motivation in a three-dimensional virtual world: An explanatory study. Australas. J. Educ. Technol. 2013, 29, 29. [CrossRef]

26. Schouten, A.P.; van den Hooff, B.; Feldberg, F. Virtual Team Work: Group Decision Making in 3D Virtual Environments. Commun. Res. 2016, 43, 180-210. [CrossRef]

27. Burgess, M.L.; Slate, J.R.; Rojas-LeBouef, A.; LaPrairie, K. Teaching and learning in Second Life: Using the Community of Inquiry (CoI) model to support online instruction with graduate students in instructional technology. Internet High. Educ. 2010, 13, 84-88. [CrossRef]

28. Hew, K.F.; Cheung, W.S. Use of three-dimensional (3-D) immersive virtual worlds in K-12 and higher education settings: A review of the research. Br. J. Educ. Technol. 2010, 41, 33-55. [CrossRef]

29. Sitzmann, T. A meta-analytic examination of the instructional effectiveness of computer-based simulation games. Pers. Psychol. 2011, 64, 489-528. [CrossRef]

30. Mikropoulos, T.A.; Natsis, A. Educational virtual environments: A ten-year review of empirical research (1999-2009). Comput. Educ. 2011, 56, 769-780. [CrossRef]

31. Inman, C.; Wright, V.; Hartman, J. Use of Second Life in K-12 and Higher Education: A Review of Research. J. Interact. Online Learn. 2011, 9, 44-63.

32. Sivunen, A.; Hakonen, M. Review of Virtual Environment Studies on Social and Group Phenomena. Small Group Res. 2011, 42, 405-457. [CrossRef]

33. Ishbel, D.; Alan, M.; Shangyi, J. A taxonomy of virtual worlds usage in education. Br. J. Educ. Technol. 2012, 43, 949-964.

34. Wang, F.; Burton, J.K. Second Life in education: A review of publications from its launch to 2011. Br. J. Educ. Technol. 2013, 44, 357-371. [CrossRef]

35. Ghanbarzadeh, R.; Ghapanchi, A.H.; Blumenstein, M.; Talaei-Khoei, A. A Decade of Research on the Use of Three-Dimensional Virtual Worlds in Health Care: A Systematic Literature Review. J. Med. Internet Res. 2014, 16, e47. [CrossRef] [PubMed]

36. Nussli, N.; Oh, K. The Components of Effective Teacher Training in the Use of Three-Dimensional Immersive Virtual Worlds for Learning and Instruction Purposes: A Literature Review. J. Technol. Teach. Educ. 2014, 22, 213-241.

37. Merchant, Z.; Goetz, E.T.; Cifuentes, L.; Keeney-Kennicutt, W.; Davis, T.J. Effectiveness of virtual reality-based instruction on students' learning outcomes in K-12 and higher education: A meta-analysis. Comput. Educ. 2014, 70, 29-40. [CrossRef]

38. Reisoğlu, I.; Topu, B.; Yılmaz, R.; Karakuş Yılmaz, T.; Göktaş, Y. 3D virtual learning environments in education: A meta-review. Asia Pac. Educ. Rev. 2017, 18, 81-100. [CrossRef] 
39. Pellas, N.; Kazanidis, I.; Konstantinou, N.; Georgiou, G. Exploring the educational potential of three-dimensional multi-user virtual worlds for STEM education: A mixed-method systematic literature review. Educ. Inf. Technol. 2017, 22, 2235-2279. [CrossRef]

40. Mantziou, O.; Papachristos, N.M.; Mikropoulos, T.A. Learning activities as enactments of learning affordances in MUVEs: A review-based classification. Educ. Inf. Technol. 2018, 23, 1737-1765. [CrossRef]

41. Pellas, N.; Mystakidis, S. A systematic review of research about game-based learning in virtual worlds. J. Univers. Comput. Sci. 2020, 26, 1017-1042.

42. Phipps, R.; Merisotis, J. What's the difference? A review of contemporary research on the effectiveness of distance learning in higher education. J. Distance Educ. 1999, 14, 102-114.

43. Zhao, Y.; Lei, J.; Yan, B.; Lai, C.; Tan, H.S. What Makes the Difference? A Practical Analysis of Research on the Effectiveness of Distance Education. Teach. Coll. Rec. 2005, 107, 1836. [CrossRef]

44. Warburton, S. Second Life in higher education: Assessing the potential for and the barriers to deploying virtual worlds in learning and teaching. Br. J. Educ. Technol. 2009, 40, 414-426. [CrossRef]

45. Moher, D.; Liberati, A.; Tetzlaff, J.; Altman, D.G.; The PRISMA Group. Preferred reporting items for systematic reviews and meta-analyses: The PRISMA statement. PLoS Med. 2009, 6, e1000097. [CrossRef] [PubMed]

46. Kitchenham, B.A. Procedures for Performing Systematic Reviews-Technical Report TR/SE-0401; Keele University: Keele, UK, 2004.

47. Songkram, N.; Chootongchai, S.; Khlaisang, J.; Koraneekij, P. Education 3.0 system to enhance twenty-first century skills for higher education learners in Thailand. Interact. Learn. Environ. 2019, 1-17. [CrossRef]

48. Grivokostopoulou, F.; Kovas, K.; Perikos, I. The Effectiveness of Embodied Pedagogical Agents and Their Impact on Students Learning in Virtual Worlds. Appl. Sci. 2020, 10, 1739. [CrossRef]

49. Fragkaki, M.; Mystakidis, S.; Hatzilygeroudis, I.; Kovas, K.; Palkova, Z.; Salah, Z.; Hamed, G.; Khalilia, W.M.; Ewais, A. Tpack instructional design model in virtual reality for deeper learning in science and higher education: From "apathy" to "empathy". In Proceedings of the 12th Annual International Conference on Education and New Learning Technologies (EDULEARN20), Palma, Spain, 6-8 July 2020; pp. 3286-3292.

50. Mystakidis, S. Distance Education Gamification in Social Virtual Reality: A Case Study on Student Engagement. In Proceedings of the 11th International Conference on Information, Intelligence, Systems and Applications (IISA 2020), Piraeus, Greece, 15-17 July 2020; pp. 1-6.

51. Freyne, J.; Coyle, L.; Smyth, B.; Cunningham, P. Relative status of journal and conference publications in computer science. Commun. ACM 2010, 53, 124. [CrossRef]

52. Drott, M.C. Reexamining the role of conference papers in scholarly communication. J. Am. Soc. Inf. Sci. 1995, 46, 299-305. [CrossRef]

53. Christopoulos, A.; Conrad, M.; Shukla, M. Interaction with Educational Games in Hybrid Virtual Worlds. J. Educ. Technol. Syst. 2018, 46, 385-413. [CrossRef]

54. Bulu, S.T. Place presence, social presence, co-presence, and satisfaction in virtual worlds. Comput. Educ. 2012, 58, 154-161. [CrossRef]

55. Konstantinidis, A.; Tsiatsos, T.; Terzidou, T.; Pomportsis, A. Fostering collaborative learning in Second Life: Metaphors and affordances. Comput. Educ. 2010, 55, 603-615. [CrossRef]

56. Hsiao, I.Y.T.; Yang, S.J.H.; Chia-Jui, C. The effects of collaborative models in second life on French learning. Educ. Technol. Res. Dev. 2015, 63, 645-670. [CrossRef]

57. Jamaludin, A.; Chee, Y.S.; Ho, C.M.L. Fostering argumentative knowledge construction through enactive role play in Second Life. Comput. Educ. 2009, 53, 317-329. [CrossRef]

58. Franetovic, M. Future Game Developers within a Virtual World: Learner Archetypes and Team Leader Attributes. J. Educ. Multimed. Hypermedia 2016, 25, 343-361.

59. Mystakidis, S.; Berki, E.; Valtanen, J. Toward Successfully Integrating Mini Learning Games into Social Virtual Reality Environments-Recommendations for Improving Open and Distance Learning. In Proceedings of the 9th Annual International Conference on Education and New Learning Technologies (EDULEARN17), Barcelona, Spain, 3-5 July 2017; pp. 968-977.

60. Bronack, S.; Riedl, R.; Tashner, J. Learning in the zone: A social constructivist framework for distance education in a 3-dimensional virtual world. Interact. Learn. Environ. 2006, 14, 219-232. [CrossRef]

61. Stiubiener, I.; Barbosa, W.; Kamienski, C.A.; Schweitzer, C.M. Using Virtual Worlds in distance learning environments. In Proceedings of the 2011 Frontiers in Education Conference (FIE), Rapid City, SD, USA, 12-15 October 2011; p. F3C-1.

62. Creswell, J.W. Educational Research: Planning, Conducting, and Evaluating Quantitative and Qualitative Research, 4th ed.; Pearson Education: Harlow, Essex, 2014.

63. Meltzoff, J. Critical Thinking about Research; American Psychological Association: Washington, DC, USA, 2007.

64. Williamson, K.M. Evidence-Based Practice: Critical Appraisal of Qualitative Evidence. J. Am. Psychiatr. Nurses Assoc. 2009, 15, 202-207. [CrossRef]

65. Turnbull, S. A Guide to UK League Tables in Higher Education; Higher Education Policy Institute: Washington, DC, USA, 2018.

66. Dickey, M.D. Three-dimensional virtual worlds and distance learning: Two case studies of Active Worlds as a medium for distance education. Br. J. Educ. Technol. 2005, 36, 439-451. [CrossRef] 
67. Drake-Bridges, E.; Strelzoff, A.; Sulbaran, T. Teaching Marketing Through a Micro-Economy in Virtual Reality. J. Mark. Educ. 2011, 33, 295-311. [CrossRef]

68. Da Silva, C.R.; Garcia, A.A.B. A collaborative working environment for small group meetings in Second Life. SpringerPlus 2013, 2, 281. [CrossRef]

69. Pellas, N.; Kazanidis, I. On the value of Second Life for students' engagement in blended and online courses: A comparative study from the Higher Education in Greece. Educ. Inf. Technol. 2015, 20, 445-466. [CrossRef]

70. Hearrington, D. Evaluation of Learning Efficiency and Efficacy in a Multi-User Virtual Environment. J. Digit. Learn. Teach. Educ. 2010, 27, 65-75. [CrossRef]

71. O'Connor, E.A. Instructional and Design Elements That Support Effective Use of Virtual Worlds: What Graduate Student Work Reveals about Second Life. J. Educ. Technol. Syst. 2010, 38, 213-234. [CrossRef]

72. Berns, A.; González-Pardo, A.; Camacho, D. Game-like language learning in 3-D virtual environments. Comput. Educ. 2013, 60, 210-220. [CrossRef]

73. Balcikanli, C. Language learning in Second Life: American and Turkish Students' Experiences. Turk. Online J. Distance Educ. 2012, 13, 131-146.

74. August, S.E.; Hammers, M.L.; Murphy, D.B.; Neyer, A.; Gueye, P.; Thames, R.Q. Virtual Engineering Sciences Learning Lab: Giving STEM Education a Second Life. IEEE Trans. Learn. Technol. 2016, 9, 18-30. [CrossRef]

75. Wiecha, J.; Heyden, R.; Sternthal, E.; Merialdi, M. Learning in a Virtual World: Experience with Using Second Life for Medical Education. J. Med. Internet Res. 2010, 12, e1. [CrossRef] [PubMed]

76. Beltrán Sierra, L.M.; Gutiérrez, R.S.; Garzón-Castro, C.L. Second Life as a support element for learning electronic related subjects: A real case. Comput. Educ. 2012, 58, 291-302. [CrossRef]

77. Girvan, C.; Tangney, B.; Savage, T. SLurtles: Supporting constructionist learning in Second Life. Comput. Educ. 2013, 61, 115-132. [CrossRef]

78. Hornik, S.; Thornburg, S. Really Engaging Accounting: Second Life ${ }^{\mathrm{TM}}$ as a Learning Platform. Issues Account. Educ. 2010, 25, 361-378. [CrossRef]

79. Mystakidis, S.; Berki, E.; Valtanen, J. Designing and implementing a big open online course by using a $3 \mathrm{~d}$ virtual immersive environment-Lessons learned. In Proceedings of the 9th Annual International Conference on Education and New Learning Technologies (EDULEARN17), Barcelona, Spain, 3-5 July 2017; pp. 8070-8079.

80. Noteborn, G.; Bohle Carbonell, K.; Dailey-Hebert, A.; Gijselaers, W. The role of emotions and task significance in Virtual Education. Internet High. Educ. 2012, 15, 176-183. [CrossRef]

81. Okita, S.Y.; Turkay, S.; Kim, M.; Murai, Y. Learning by teaching with virtual peers and the effects of technological design choices on learning. Comput. Educ. 2013, 63, 176-196. [CrossRef]

82. Wang, C.X.; Calandra, B.; Hibbard, S.T.; McDowell Lefaiver, M.L. Learning effects of an experimental EFL program in Second Life. Educ. Technol. Res. Dev. 2012, 60, 943-961. [CrossRef]

83. Ward, T.; Falconer, L.; Frutos-Perez, M.; Williams, B.; Johns, J.; Harold, S. Using virtual online simulations in Second Life ${ }^{\circledR}$ to engage undergraduate psychology students with employability issues. Br. J. Educ. Technol. 2015, 47, 918-931. [CrossRef]

84. Ramírez, J.; Rico, M.; Riofrío-Luzcando, D.; Berrocal-Lobo, M.; De Antonio, A. Students' Evaluation of a Virtual World for Procedural Training in a Tertiary-Education Course. J. Educ. Comput. Res. 2017, 56, 23-47. [CrossRef]

85. Vrellis, I.; Avouris, N.; Mikropoulos, T.A. Learning outcome, presence and satisfaction from a science activity in Second Life. Australas. J. Educ. Technol. 2016, 32. [CrossRef]

86. Keskitalo, T.; Pyykkö, E.; Ruokamo, H. Exploring the meaningful learning of students in second life. Educ. Technol. Soc. 2011, $14,16-26$.

87. Omale, N.; Omale, N.; Hung, W.; Luetkehans, L.; Cooke-plagwitz, J. Learning in 3-D multiuser virtual environments: Exploring the use of unique 3-D attributes for online problem-based learning. Br. J. Educ. Technol. 2009, 40, 480-495. [CrossRef]

88. Pellas, N. The influence of computer self-efficacy, metacognitive self-regulation and self-esteem on student engagement in online learning programs: Evidence from the virtual world of Second Life. Comput. Hum. Behav. 2014, 35, 157-170. [CrossRef]

89. Tapsis, N.; Tsolakidis, K.; Vitsilaki, C. Virtual Worlds and Course Dialogue. Am. J. Distance Educ. 2012, 26, 96-109. [CrossRef]

90. Rogers, L. Developing simulations in multi-user virtual environments to enhance healthcare education. Br. J. Educ. Technol. 2011, 42, 608-615. [CrossRef]

91. Downey, S.; Mohler, J.; Morris, J.; Sanchez, R. Learner perceptions and recall of small group discussions within 2D and 3D collaborative environments. Australas. J. Educ. Technol. 2012, 28, 28. [CrossRef]

92. Erlandson, B.E.; Nelson, B.C.; Savenye, W.C. Collaboration modality, cognitive load, and science inquiry learning in virtual inquiry environments. Educ. Technol. Res. Dev. 2010, 58, 693-710. [CrossRef]

93. Petrakou, A. Interacting through avatars: Virtual worlds as a context for online education. Comput. Educ. 2010, 54, 1020-1027. [CrossRef]

94. Schiller, S.Z.; Mennecke, B.E.; Nah, F.F.-H.; Luse, A. Institutional boundaries and trust of virtual teams in collaborative design: An experimental study in a virtual world environment. Comput. Hum. Behav. 2014, 35, 565-577. [CrossRef]

95. Ozonur, M.; Yanpar Yelken, T.; Sancar Tokmak, H. Social presence and motivation in online environments: Second Life versus the Enocta Learning Management System/Adobe Connect. Australas. J. Educ. Technol. 2018, 34. [CrossRef] 
96. Edirisingha, P.; Nie, M.; Pluciennik, M.; Young, R. Socialisation for learning at a distance in a 3-D multi-user virtual environment. Br. J. Educ. Technol. 2009, 40, 458-479. [CrossRef]

97. Anderson, T. Getting the Mix Right Again: An Updated and Theoretical Rationale for Interaction. Int. Rev. Res. Open Distrib. Learn. 2003, 4, 4. [CrossRef]

98. Entwistle, N.J.; Peterson, E.R. Conceptions of learning and knowledge in higher education: Relationships with study behaviour and influences of learning environments. Int. J. Educ. Res. 2004, 41, 407-428. [CrossRef]

99. Steils, N.; Tombs, G.; Mawer, M.; Savin-Baden, M.; Wimpenny, K. Implementing the liquid curriculum: The impact of virtual world learning on higher education. Technol. Pedagog. Educ. 2015, 24, 155-170. [CrossRef]

100. Scardamalia, M.; Bereiter, C. Knowledge Building: Theory, Pedagogy, and Technology. In The Cambridge Handbook of the Learning Sciences; Keith Sawyer, R., Ed.; Cambridge University Press: Cambridge, UK, 2006; pp. 97-115. ISBN 0-521-84554-8.

101. Ryan, R.M.; Deci, E.L. Self-determination theory and the facilitation of intrinsic motivation, social development, and well-being. Am. Psychol. 2000, 55, 68-78. [CrossRef] [PubMed]

102. Makransky, G.; Petersen, G.B. Investigating the process of learning with desktop virtual reality: A structural equation modeling approach. Comput. Educ. 2019, 134, 15-30. [CrossRef]

103. Barab, S.; Pettyjohn, P.; Gresalfi, M.; Volk, C.; Solomou, M. Game-based curriculum and transformational play: Designing to meaningfully positioning person, content, and context. Comput. Educ. 2012, 58, 518-533. [CrossRef]

104. Metcalf, S.J.; Reilly, J.M.; Kamarainen, A.M.; King, J.; Grotzer, T.A.; DeDe, C. Supports for deeper learning of inquiry-based ecosystem science in virtual environments-Comparing virtual and physical concept mapping. Comput. Hum. Behav. 2018, 87, 459-469. [CrossRef]

105. Dalgarno, B.; Lee, M.J.W. What are the learning affordances of 3-D virtual environments? Br. J. Educ. Technol. 2009, 41, 10-32. [CrossRef]

106. Mystakidis, S.; Berki, E. The Case of Literacy Motivation: Playful 3D immersive learning environments and problem-focused education for blended digital storytelling. Int. J. Web-Based Learn. Teach. Technol. 2018, 13, 64-79. [CrossRef]

107. Schwaiger, M. (Ed.) Boosting Virtual Reality in Learning; Focus Europe: Graz, Austria, 2020.

108. Chaudhary, S.; Zhao, Y.; Berki, E.; Valtanen, J.; Li, L.; Helenius, M.; Mystakidis, S. A Cross-Cultural and Gender-Based Perspective for Online Security: Exploring Knowledge, Skills and Attitudes of Higher Education Students. IADIS Int. J. WWW/Internet 2015, $13,57-71$.

109. Metzinger, T.K. Why Is Virtual Reality Interesting for Philosophers? Front. Robot. AI 2018, 5, 101. [CrossRef] [PubMed]

110. Berki, E. Reflections on e-Learning in the Time of Coronavirus: The Nordic Experience and Ethical Considerations-Back to the Future with the e-Learners Manifesto. In Proceedings of the 25th Annual INSPIRE Conference, Online, 16 July 2020; Uhomoibhi, J., Dewar, E., Georgiadou, E., Linecar, P., Marchbank, P., Ross, M., Staples, G., Eds.; pp. 21-52.

111. Jäkälä, M.; Berki, E. Communities, communication and on-line identities. In Digital Identity and Social Media; Warburton, S., Hatzipanagos, S., Eds.; IGI Global: Hershey, PA, USA, 2013; pp. 1-13. ISBN 9781466619159.

112. Berki, E.; Kandel, C.; Zhao, Y.; Chaudhary, S. A Comparative Study of Cyber-Security Knowledge in Higher Education Institutes of Five Countries. In Proceedings of the EDULEARN17 Conference, Barcelona, Spain, 3-5 July 2017; pp. $2796-2806$.

113. Berki, E.; Georgiadou, E. Outcome-Centred Evaluation of Traditional and Open and Distance Teaching and Learning Methods for Software Engineers. In Proceedings of the 10th Anniversary Conference European Distance Education Network, Stockholm, Sweden, 10-13 June 2001; Szucs, A., Wagner, E., Holmberg, C., Eds.; pp. 13-19.

114. Johansson, A. 9 Ethical Problems with VR We Still Have to Solve. Available online: https://thenextweb.com/contributors/2018 /04/18/9-ethical-problems-vr-still-solve/ (accessed on 20 December 2020). 